\title{
İlişki Özyeterlik Ölçeğinin Türkçeye Uyarlanması: Geçerlik ve Güvenirlik Çalışması ${ }^{1}$
}

\author{
DOI: 10.26466/opus.510391 \\ * \\ $\underline{\text { Yunus Akan }}^{*}$ \\ *Dr. Öğretim Üyesi, Muş Alparslan Üniversitesi, Eğitim Fakültesi, Muş / Türkiye \\ E-Posta: yakan.86@hotmail.com \\ ORCID: 0000-0003-3946-7356
}

\section{Öz}

Bu çalışmada Lopez, Morúa ve Rice (2007) tarafından geliştirilen "İlişki Özyeterlik Ölçeği" Türkçe'ye uyarlanmıştır. Çalışmaya Mersin'de yaşayan ve bir eşe (evli, nişanll, sevgili vb.) sahip 230 yetişkin iki hafta arayla iki kez katılmıştır. Ölçeğin geçerliği için 35 maddelik denemelik formu üzerinden açımlayıcı ve doğrulayıcı doğrulayıcı faktör analizi yapılmıştır. Ölçeğin güvenirliliğini test etmek için Cronbach Alfa değeri ve test tekrar testi korelasyon katsayısı hesaplanmıştır. KMO değerinin .85 olduğ u belirlenmiş ve "mükemmel" derecede yeterli olduğu ortaya çıkmıştır. Bartlett Küresellik testi sonucunda ise Ki-kare değeri istatistiksel olarak anlamlı bulunmuştur [X2=2967,50; $p=0.00$ ). Yapılan açımlayıcı faktör analizi sonucu özdeğeri 1'in üzerinde, en az üç maddeye sahip, açıkladığı varyans değeri \%5' in üzerinde olan ve toplam varyansın \%49,91'ini açıklayan 3 faktörlü bir yapı elde edilmiştir. Yapılan doğrulayıcı faktör analizi sonucunda uyum indeksi değerleri RMSEA=0.061, NFI=0.91, CFI=0.95, IFI=0.95, RFI=0.90, GFI=0.91 ve AGFI=0.89 olarak anlamlı bulunmuştur. Güvenilirlik çalışmasında tüm ölçek için Cronbach Alfa değeri .81; "Karşllıklık", "Duygusal Kontrol" ve "Farklılaşma" alt boyutları için sirasıyla .81, .75 ve .61 bulunmuştur. Test tekrar testi korelasyon katsayısı tüm ölçek için .90, alt boyutlar içinde sirasıyla .92, .86. ve ,80 bulunmuştur. "İlişki Özyeterlik Ölçeği", 16 maddelik 3 alt boyutlu formuyla Türkiye'deki 18 yaş üstü bireylere uygulanabilir geçerli ve güvenilir bir ölçek olduğu sonucuna varılmıştır.

Anahtar Kelimeler: Eş, evlilik, ilişki, özyeterlik, ölçek uyarlama

\footnotetext{
${ }^{1}$ Bu çalışma, "Şiddeti Azaltma Psiko-Eğitim Programı'nın (ŞAPP) Eşine Şiddet Uygulayan Erkeklerin Saldırganlık, Duygu Yönetimi ve Ilişki Özyeterlik Düzeylerine Etkisinin Incelenmesi" başlıklı doktora tezinden üretilmiştir. Ayrıca 25-27 Ekim 2018 tarihleri arasında yapılan 20. Uluslararası Psikolojik Danışmanlık ve Rehberlik kongresinde bildiri olarak sunulmuştur.
}

OPUS (c) Uluslararası Toplum Araştırmaları Dergisi-International Journal of Society Researches ISSN:2528-9527 E-ISSN : 2528-9535

http://opusjournal.net 


\title{
Adaptation of Relationship Self-Efficacy Scale to Turkish: Validity And Reliability Study
}

\begin{abstract}
In this study, the Relationship Self-Efficacy Scale developed by Lopez, Morúa and Rice (2007) was adapted to Turkish. 230 adults who live in Mersin and were in a relationship (spouse, fiancélfiancée, or other partner) participated in the adaptation of scale by completing it twice two weeks apart. For the validity of the scale, explanatory factor analysis and confirmatory factor analysis were performed on the 35-item scale. The KMO value was found to be .85, and this was found to be "excellent". As a result of Bartlett'ssphericity test, thechi-square value was found to be statistically significant. As a result of the exploratory factor analysis, a 3-factor structure with eigenvalues over 1 having at least three substances, having a variance of more than $5 \%$ and explaining $49.91 \%$ of the total variance, was obtained. As a result of the confirmatory factor analysis, the fit index values were found to be significant. In the reliability study, the Cronbach'salpha value for the whole scale was .81; for the sub-dimensions of "Mutuality", "Emotional Control" and "Differentiation" it was .81, .75 and .61, respectively. The test-retest correlation coefficient was .90 for the whole scale, and .92, .86. and 80 for the sub-dimensions, respectively.
\end{abstract}

Keywords: Spouse, marriage, relationship, self-efficacy, scale adaptation 


\section{Giriş}

Özyeterlik kavramı ilk defa Bandura tarafından vurgulanmıştır. Bandura'ya (1997) göre özyeterlik, bir işi uygulamada veya başarmada bireyin kendi kapasitesine olan inancını ifade eder. Özyeterlik bireyin içinde var olan davranışların ortaya çıkmasında ve yeni davranışların oluşmasında son derece önemlidir. Özyeterlik inancına sahip bireylerin bir işi başarmada daha fazla çaba gösterme ve zorluklara daha fazla dayanma eğilimi içerisindedirler (Bandura, 1997). Özyeterlik ile ilgili yapılan araştırmalarda özyeterliliğin motivasyonu (McCrudden, Perkins ve Putney, 2005) ve başarıyı artırdığı (Karahan ve Balat, 2011), yaşam (Sahranç, 2007) ve iş doyumunu etkilediği (Gençtürk, 2008), olumlu davranışları artırdığ1 (Zengin, 2003) ve mesleğe yönelik olumlu tutumlar geliştirilmesini sağladığı (Doğan, 2013) görülmüştür. Ayrıca özyeterlik inancına sahip bireylerin daha az tükenmişlik yaşadıkları görülmüş (Karahan ve Balat, 2011) ve özyeterlik inancı düşük bireylerin daha fazla duygusal yorgunluk yaşadığı belirlenmiştir (Çimen, 2007).

Erkeklerin kadınlara uyguladığı eş şiddetinin temelinde erkeklerin kendine güven sorunu olduğu yapılan araştırmalarda ortaya çıkmıştır (Jacobson ve Gottman, 1998; Riggs, Caulfield ve Street, 2000; Peralta, Tuttle ve Steele, 2010). Erkeklerde özyeterlik inancını geliştirmek ve erkeklerin kendine olan güveni artırmak şiddet gibi olumsuz davranışları azaltabilir. Zengin (2003) yaptığı bir araştırmada özyeterlik inancı geliştiren insanların şiddet gibi olumsuz davranışlarının azaldığını ifade etmiştir.

Özyeterlik inancının ikili ilişkilerde de gelişmiş olması çok önem atfetmektedir; çünkü yetişkin bir bireyin en önemli gelişim görevlerinden birisi de tatmin edici, samimi, yakın ilişkiler kurma ve sürdürmedir (Collins, Cooper, Albino ve Allard, 2002). Tatmin edici samimi ilişkiler kurma ve sürdürmede bireyin sahip olduğu kapasite önemli olmaktadır ve üretken bir şekilde yakın ilişkiler kurulabilmesi için bireyin kendi kapasitesine olan inancının yüksek olması gerekmektedir. Burada ilişki özyeterliği kavramının önemi ortaya çıkmaktadır. İlişki özyeterliği, tatmin edici samimi ilişkiler kurma ve sürdürmede bireyin sahip olduğu kapasitesine olan inancıdır. Yüksek ilişki özyeterliğine sahip bireyler, ilişkilerde kaçmaktan ziyade daha fazla yakınlaşmaya, engellere daha fazla katlanmaya, engelleri aşmak için daha fazla çaba göstermeye ve ilişkiyi 
devam ettirmeye daha istekli olmaktadır (Lopez ve Lent, 1991). Yakın ve tatmin edici bir ilişkinin özellikleri arasında; beraber etkinliklere katılmak, karşı cinse destek ve güven sağlamak, ilişkiye ilişkin kişisel düşünce ve duygularını açıklamak, anlaşmazlıklar sırasında birlikte sorunu çözmeye çalışmak ve açı iletişim kurmak vardır (Canary ve Stafford, 1992). Harvey ve Omarzu (1997) yakın ve tatmin edici ilişkileri sürdürebilmek için gerekli olan öğeleri; kabul ve saygı, ortakların düşünce, duygu ve davranışlarındaki karşılıklık olarak belirtmişlerdir. Cassidy (2001) ise yakın ve tatmin edici ilişkiler için kişisel ihtiyaçların tatmin olması, yetenekleri göstermeye imkân tanınması, rahat ve özerk hissetmek, açık iletişim kurabilme kabiliyeti öğelerinin olması gerektiğini ifade etmiştir.

İlişki özyeterliğinin eşlerin birbirine karşı oluşturduğu bağlanma stilleri ve eş şiddetiyle aralarında yüksek düzeyde ilişki olduğu görülmüştür (Craparo, Gori, Petruccelli, Cannella ve Simonelli, 2014). Cinayet suçundan hüküm giymiş erkeklerle yapılan bir araştırmada erkeklerin uyguladığ1 şiddet suçu ile ilişkideki güvensiz bağlanma arasında ilişki bulunmuştur (Ayan, 2013). Bazen eşler arasındaki çatışmalardan dolayı korku dolu bir bağlanma stili devreye girmekte ve erkek kaybetmeyi engellemek için şiddete başvurabilmektedir (Dutton, 2010). İlişki özyeterliğine sahip bireyler ilişkilerinde güvenli bağlanma stiline sahiptirler ve güvene dayalı, sağlıklı iletişim temellerine kurulmuş, korku ve kaygılardan arınmış ve çatışmalarda yapıcı çözümler kullanılan ilişkiler kurarlar.

Eş şiddeti uygulayan erkeklerde ilişki özyeterlik inancını geliştirmenin erkeklerin kendine olan güvenini artırdığı gibi şiddet davranışını azalttığı görülmektedir. Akan ve Kıran (2017) tarafından yapılan bir araştırmada şiddet uygulayan erkeklerin tatmin edici, samimi, yakın ilişkiler kurma ve sürdürmede zorluk yaşadıkları, ilişkilerini otoriteye dayalı bir düzen üzerine kurdukları ve ilişkilerinde yaşanan zorlukları eşine şiddet uygulayarak çözmeye çalıştıkları görülmüştür. Halbuki ilişki özyeterliğine sahip ve kendine güvenen erkekler, ilişkilerde kaçmaktan ziyade daha fazla yakınlaşmaya, engellere daha fazla katlanmaya, engelleri aşmak için daha fazla çaba göstermeye ve ilişkiyi devam ettirmeye daha istekli olmaktadır (Lopez ve Lent, 1991). Yapılan başka bir araştırmada şiddeti önleme programları tamamlandıktan sonra erkeklerin, ilişkinin eşitlik üzerine kurulması gerektiğini düşünme ve ilişkide açık bir iletişim tarzını benimseme gibi bazı ilişki özyeterlik kısımlarında gelişme gösterdikleri 
görülmüştür (Dangelo, 2005). Bütün bunlar ilişki özyeterlik inancının özellikle flört ve evlilik ilişkilerinde eşler arasındaki ilişkinin kalitesi ve ilişkiden alınan doyum üzerinde ne kadar etkili olduğunu ve eşlerin ilişki özyeterlik inancının düşük olmasının ilişkilerde büyük sorunlara sebep olacağını göstermektedir. Tür-kiye'de de, eşler arasında ilişkilerde yaşanan anlaşmazlıklar veya çatışmalar, her sene yüzbinlerce eşin boşanmasına, binlerce kadının öldürülmesine ve parçalanmış ailelerde yüzbinlerce çocuğun büyük travmalar yaşayarak büyümesine sebep olmaktadır. Alanyazın incelendiğinde bu kadar önem atfedilen eşler arasındaki ilişki özyeterliği kavramı üzerinde ülkemizde çalışma yapılmadığı görülmektedir. Ayrıca ülkemizde ikili ilişkilerde eşlerin ilişki özyeterlik becerisini ölçmeye yönelik bir ölçme aracı bulunmaması nedeniyle bu çalışmada Lopez ve diğerleri (2007) tarafından geliştirilen "İlişki Özyeterlik Ölçeği" nin Türkçe'ye uyarlanması amaçlanmıştır.

\section{Yöntem}

$\mathrm{Bu}$ araştırma, eşlerin ilişki özyeterlik düzeylerini belirlemeye yönelik bir ölçek uyarlama çalışmasıdır. Ölçek uyarlama sürecinde bazı aşamalar izlenmiştir. Ölçek uyarlama sürecine yönelik izlenen aşamalar aşağıda sunulmuştur.

\section{Çalışma Grubu}

Bu ölçek uyarlama çalışmasına Mersin'de yaşayan ve bir eşe (evli, nişanlı, sevgili vb.) sahip 230 yetişkin iki hafta arayla iki kez katılmıştır. Katılımcıların \% 56,5'i erkek, \% 43,5'i kadındır ve yaşları 18 ile 50 arasında değişmektedir. Katılımcların \%50'i evli, \%33,5'i sevgili, \% 7,4'ü sözlünişanlı ve \% 9,1'i ise diğeri (boşanmış, ayrı...) oluşmaktadır.

\section{Veri Toplama Araçları}

Veri toplama aracı olarak "İlişki Özyeterlik Ölçeği” nin denemelik formu kullanılmıştır. Lopez ve diğerleri (2007) tarafından geliştirilen ölçeğin 
orijinal formu, 25 maddeden oluşmaktadır. Ölçekte, yetişkinlerin partnerleriyle (eş, sevgili, nişanlı vb.) ilişkilerinde yaşadığı durumlar ile ilgili ifadeler yer almaktadır. Ölçekte ters çevrilecek olumsuz madde yoktur ve tüm maddeler olumlu ifadelerden oluşmaktadır. Ölçekten alınan toplam puanın yüksekliği, ilişki özyeterlik beceri düzeyinin yüksek olduğunu göstermektedir. Ölçeğin denemelik formu, bir partnerle yakın ilişkiye sahip 395'i kadın 213'ü erkek toplam 608 yetişkin üzerinde uygulanmıştır. Analizler, ölçeğin 35 maddelik denemelik formunun uygulandığı 608 örneklem üzerinden elde edilen verilerle gerçekleşmiştir. Yapılan açımlayıcı faktör analizi sonucu ölçeği \%59 oranında açılayan 25 maddelik 3 alt boyutlu bir yapı ortaya çıkmıştır. Bu alt boyutlar "Karşılıklık (16 madde)", "Duygusal Kontrol (5 madde)" ve "Farklılaşma (4 madde)" dır. Güvenirlik çalışmalarında ise, ölçeğin iç tutarlık katsayıları "Tüm ölçek için" 0,94, "Karşılıklık" alt boyutu için 0,93, "Duygusal Kontrol" alt boyutu için 0,85 ve "Farklılaşma" alt boyutu için 0,79'dur. Yapılan doğrulayıc faktör analizi sonucunda uyum indeks değerlerinin kabul edilebilir seviyede olduğu ortaya çıkmıştır (CFI=,95, SRMR=,063, RMSEA= ,072) (Lopez ve diğerleri, 2007). Ölçek, araştırmacı tarafından 2018 yılında Türkçe'ye uyarlanmıştır. İlişki özyeterlik ölçeğinin Türkçeye uyarlanması sürecine ilişkin bilgiler aşağıda verilmiştir.

\section{İlişki Özyeterlik Ölçeğinin Geliştirilmesi Süreci}

Öncelikle “İlişki Özyeterlik Ölçeği'nin 35 maddelik denemelik formuna ulaşılarak, formda yer alan tüm maddeler üzerinden uyarlama çalışması yapılmıştır. Ölçeğin denemelik formunda yer alan 35 madde, önce araştırmacı tarafından daha sonra da dört alan uzmanı tarafından Türkçe'ye çevrilmiştir. Daha sonra bu çeviriler bir araya getirilerek hepsinin ortak yönleri aranmış ve farklılık gösteren ifadeler, çeviri yapan kişiler ile görüşülerek ortak bir cümle haline getirilmiştir. Uzman görüşüne dayanarak oluşturulan Türkçe formu, tekrar İngilizceye çevrilmiştir. Ölçeğin denemelik formunun orijinal hali ile tekrar İngilizceye çevrilmiş hali dört alan uzmanına incelettirilerek, ikisi arasında farklılığın olmadığ 1 yönünde ortak görüşe varılmıştır. Aşamalı olarak Türkçeye çevirisi tamamlanan form, Türkçe uzmanlarının görüşüne sunulup önerileri alınmıştır. Ölçeğin Türkçe formunun bu ilk şeklinin dil ve anlaşılırlığını test etmek 
ve maddelerin Türkiye'de 18 yaş üstü bireylerin yaşam kültürüne uygunluğunu belirlemek amacı ile bir partnere sahip (eş, sevgili, nişanlı vb.) 10 yetişkine ön uygulaması yapılmıştır. Geri bildirimler doğrultusunda ölçeğe son şekli verilerek uygulamaya hazır hale getirilmiştir. Daha sonra "İlişki Özyeterlik Ölçeği"nin 35 maddelik denemelik formu, 18 yaş üstü 230 bireye 15 gün arayla iki kez uygulanmıştır.

\section{Verilerin Analizi}

Ölçeğin geçerliği için 35 maddelik denemelik formu üzerinden SPSS 21 programı kullanılarak açımlayıcı faktör analizi ve Lisrel 9.2 programı kullanılarak doğrulayıcı faktör analizi yapılmıştır. Açımlayıcı faktör analizi için varimax dik döndürme tekniği kullanılmıştır. Çok faktörlü yapı söz konusu oldugu durumlarda varimax daha uygun bir seçim oldugu söylenebilir. Varimax yöntemiyle faktörler, kendileriyle yüksek ilişki veren maddeleri bulurlar ve faktörler daha kolay yorumlanabilir. Varimax yönteminde faktörler arasında yüksek düzeyde anlamlı bir ilişki olmadığı düşüncesine dayalı olan dik döndürme yapılır ve dik döndürmede faktörler, eksenlerin konumu değiştirmeksizin (aynı açıyla) döndürülür (Tabachnick ve Fideli, 2001). Bu verilerden yola çıkılarak, çok faktörlü bir yapı söz konusu olduğundan, tüm faktörler arasında yüksek düzeyde bir ilişki olmadığından ve daha iyi yorum yapılabilmesi için faktör varyanslarının maksimum olmasını sağlayacak biçimde varimax dik döndürme tekniğiyle döndürme yapılmıştır. Ölçeğin güvenirliliğini test etmek için Cronbach Alfa değeri ve test tekrar testi kore-lasyon katsayısı hesaplanmiştır. 


\section{Bulgular}

Araştırma kapsamında toplanan veriler üzerinden faktör analizinin yapılabilmesi için önce örneklem büyüklügüüne bakılmıştır. Tabachnick ve Fidell (2001) 50 örneklemi çok zayıf, 100 örneklemi zayıf, 200'ü yeterli, 300'ü iyi, 500'ü çok iyi 1000 ve üzerini ise mükemmel olarak değerlendirmektedir. Faktör analizinin yapılabilmesi için gerekli görülen örneklem büyüklüğü incelendiğinde, 230 örneklem sayısının yeterli olduğu görülmüştür.

İlişki özyeterlik ölçeğinin yapı geçerliğini belirlemeden önce veri setinin faktör analizine uygunluğu değerlendirilmiş ve bunun için KaiserMayer-Olkin (KMO) değeri ve Bartlett testi sonuçları incelenmiştir. İlk olarak veri setindeki kayıp değerler incelenmiş, tüm veri setlerinde kayıp değerlerin \%5'in altında olduğu ve herhangi bir örüntü sergilemediği belirlenmiştir. Daha sonra yapılan analiz sonucunda KMO değerinin .85 olduğu belirlenmiştir. Faktör analizine uygunluk için KMO değerine bakılır ve 0.6 üstündeki değerler yeterli (Tabachnick ve Fidell, 2001); 0,80 üstü değerler ise mükemmel sayılabilir (Büyüköztürk, 2012). KMO değerinin "mükemmel" (Büyüköztürk, 2012) derecede ve yeterli olması (Tabachnick ve Fidell, 2001), örneklem büyüklügünün ve maddeler arasındaki korelasyonun faktör analizine uygun olduğunu göstermektedir. Bartlett Küresellik testi sonucunda ise Ki-kare değerinin istatistiksel olarak anlamlı olması [X2=2967,509; p=0.00) korelasyon matrisinde bazı maddelerin yüksek düzeyde ilişkili olduğu konusunda kanıt sağlamış ve verilerin faktör analizi için uygun olduğunu göstermiştir. Ayrıca ölçek maddelerinin her birinde ve madde birleşimlerinde aykırı değerler incelenmiştir (Tabachnick ve Fidell, 2007).

Verilerin faktör analizine uygunluğu test edildikten sonra önce veri setine açımlayıcı faktör analizi (AFA) ve daha sonra da aynı veri üzerinden doğrulayıcı faktör analizi (DFA) yapılmış ve elde edilen sonuçlar aşağıdaki tablolarda verilmiştir.

Yapılan temel bileşenler analizi sonucuna göre döndürme öncesi faktörlerin özellikleri Tablo 1'de gösterilmiştir. 
Tablo 1. Yapılan Temel Bileşenler Analizi Sonuçlarına Göre Döndürme Öncesi Faktörlerin Özellikleri

\begin{tabular}{lcccccc}
\hline & \multicolumn{3}{c}{ Başlangıç Özdeğerleri } & \multicolumn{3}{c}{ Kare Yüklerinin Döndürme Toplamları } \\
Faktör & $\begin{array}{c}\text { Özdeğe } \\
\text { Açıladığı }\end{array}$ & $\begin{array}{c}\text { Toplam } \\
\text { Varyans }\end{array}$ & Özdeğer & $\begin{array}{c}\text { Açkladı̆̆ } \\
\text { Varyans }\end{array}$ & $\begin{array}{c}\text { Toplam } \\
\%\end{array}$ \\
\hline 1 & 8,64 & 24,6 & 24,68 & 3,07 & 8,79 & 8,79 \\
2 & 2,68 & 7,67 & 32,36 & 3,05 & 8,73 & 17,53 \\
3 & 1,76 & 5,03 & 37,40 & 2,89 & 8,27 & 25,80 \\
4 & 1,69 & 4,82 & 42,23 & 2,83 & 8,10 & 33,90 \\
5 & 1,44 & 4,12 & 46,35 & 2,19 & 6,27 & 40,17 \\
6 & 1,40 & 4,01 & 50,37 & 1,86 & 5,31 & 45,49 \\
7 & 1,29 & 3,71 & 54,08 & 1,77 & 5,07 & 50,57 \\
8 & 1,19 & 3,39 & 57,48 & 1,75 & 5,00 & 55,57 \\
9 & 1,12 & 3,21 & 60,70 & 1,45 & 4,15 & 59,73 \\
10 & 1,09 & 3,13 & 63,83 & 1,43 & 4,10 & 63,83 \\
.. &.. &.. &.. & & & \\
34 &, 22 &, 64 & 99,46 & & & \\
35 &, 18 &, 53 & 100,0 & & & \\
\hline
\end{tabular}

Tablo 1'deki veriler incelendiğinde yapılan temel bileşenler analizi sonucunda özdeğeri 1'in üzerinde olan ve toplam varyansı \%63.9 oranında açıklayan 10 faktörlü bir yapı ortaya çıkmıştır. Tablo 1'de görüldüğü gibi ölçek maddeleri 10 faktör altında toplandığı görülmüştür. Ayrıca çok sayıda binişik madde olduğu $(5,18 \ldots)$ ve bazı alt boyutlarda üçten az madde (10. alt boyut: 11 ve 17. madde...) yer aldığı belirlenmiştir.

Açımlayıcı faktör analizinde her bir maddeye yüklenen madde faktör yük değeri 30 ve üzeri olması gerekir (Kline, 1994; Büyüköztürk, 2012). Ayrıca faktörler altında maddelere yüklenen iki yük değeri arasındaki fark en az .10 olması gerekir; yoksa bu varsayımı ihlal eden maddeler binişik madde olarak adlandırılır (Büyüköztürk, 2012). Yapılan AFA sonucunda madde faktör yük değer .30 'un altında olan ve binişik madde olarak adlandırılan maddeler sırasıyla atılmıştır. Her madde çıkarma işleminden sonra yeni ölçek formuna tekrardan AFA yapılmış ve maddelerin faktörlere dağılımı ile maddelerin faktörler altında aldıkları değerler incelenmiştir. Ayrıca bir alt faktörde en az üç madde yer almasına madde çıarma işlemi yapılırken dikkat edilmiştir (Büyüköztürk, 2012). Atılması gereken tüm maddeler çıkarıldıktan sonra deneme formunda kalan 16 madde ile yeniden analiz yapılmış ve elde edilen sonuçlar Tablo 2'de açıklanmıştır. 
Tablo 2. Faktör Analizine Yönelik Varimax Döndürme Sonrası Temel Bileşen Analizi Sonuçları

\begin{tabular}{|c|c|c|c|c|c|}
\hline Faktör Adı & $\begin{array}{l}\text { Madde } \\
\text { Numaras1 }\end{array}$ & $\begin{array}{c}\text { Ortak Faktör } \\
\text { Varsansı }\end{array}$ & Faktör 1 & Faktör 2 & Faktör 3 \\
\hline \multirow{9}{*}{ Karşılıklık } & 18 & 65 & ,74 & & \\
\hline & 13 &, 50 & 69 & & \\
\hline & 20 &, 55 & 67 & & \\
\hline & 27 & 42 & 64 & & \\
\hline & 7 & 45 & 63 & & \\
\hline & 19 & 43 & 63 & & \\
\hline & 12 & 48 & 62 & & \\
\hline & 10 & 40 &, 53 & & \\
\hline & 14 &, 31 & 44 & & \\
\hline \multirow{4}{*}{$\begin{array}{l}\text { Duygusal } \\
\text { kontrol }\end{array}$} & 33 & 68 & & 82 & \\
\hline & 21 & 64 & & 76 & \\
\hline & 34 &, 54 & & ,70 & \\
\hline & 16 &, 50 & & 64 & \\
\hline \multirow{3}{*}{ Farklılaşma } & 11 &, 56 & & & ,74 \\
\hline & 17 & 48 & & & 66 \\
\hline & \multirow{2}{*}{$\begin{array}{l}1 \\
\text { Özdeğer }\end{array}$} & 44 & & &, 59 \\
\hline Faktör & & \multicolumn{2}{|c|}{ Varyans (\%) } & \multicolumn{2}{|c|}{ Toplam Varyans (\%) } \\
\hline 1 & 3,84 & \multicolumn{2}{|l|}{24,01} & \multicolumn{2}{|c|}{24,01} \\
\hline 2 & 2,44 & \multicolumn{2}{|l|}{15,26} & \multicolumn{2}{|c|}{39,28} \\
\hline 3 & $\begin{array}{l}2,4+4 \\
1,70\end{array}$ & \multicolumn{2}{|l|}{10,63} & \multicolumn{2}{|c|}{49,91} \\
\hline
\end{tabular}

Tablo 2'de görüldüğü gibi her bir maddenin ortak bir faktördeki varyansı birlikte açıklama oranları incelenmiş ve bu değerlerin .31 ile .68 arasında değer aldığı gözlenmiştir. Kalaycı (2014) faktör analizinde ortak faktör varyansı .30' dan düşük olan değişkenlerin analizden çıkarılmasının açıklanan toplam varyans değerini yükselteceğini belirtmiştir. Değerler incelendiğinde bütün değerlerin $.30^{\prime}$ dan yüksek olduğu gözlenmiştir. Ayrica her bir alt faktöre yüklenen maddelerin 0,30 'un üstünde olduğu ve faktörler altında maddelere yüklenen iki yük değeri arasındaki fark en az .10 'dan fazla olduğu ortaya çıkmıştır. Elde edilen üç faktörlü yapıda faktörlerin birincisi 7, 10, 12, 13, 14, 18, 19, 20, 27. maddelerinden oluşan "Karşılıklık" alt boyutudur. İkincisi 16, 21, 33, 34. maddelerinden oluşan "Duygusal Kontrol" ve üçüncüsü ise 1, 11, 17. maddelerinden oluşan "Farklılaşma" alt boyutudur. "Karşlıklık" faktöründe yer alan maddelerin yük değerleri .44-.74, "Duygusal Kontrol" faktöründe yer alan maddelerin yük değerleri .64 -.82 ve "Farklılaşma" faktöründe yer alan 
maddelerin yük değerleri .59-.74 arasındadır. Sonuç olarak özdeğeri 1'in üzerinde, en az üç maddeye sahip, açıladığı varyans değeri \%5'in üzerinde olan ve toplam varyansın \%49,91'ini açılayan 3 faktörlü bir yapı elde edilmiştir. Kline (1994), ölçme aracıyla açıklanan toplam varyansın \%40 oranında olması gerektiğini vurgular. Bu durum göz önünde bulundurulduğunda açıklanan toplam varyansın $(\% 49,91)$ yeterli olduğu söylenebilir. Üç faktörlü yapıya ait Scree Plot grafiği Şekil 1'de verilmiştir.

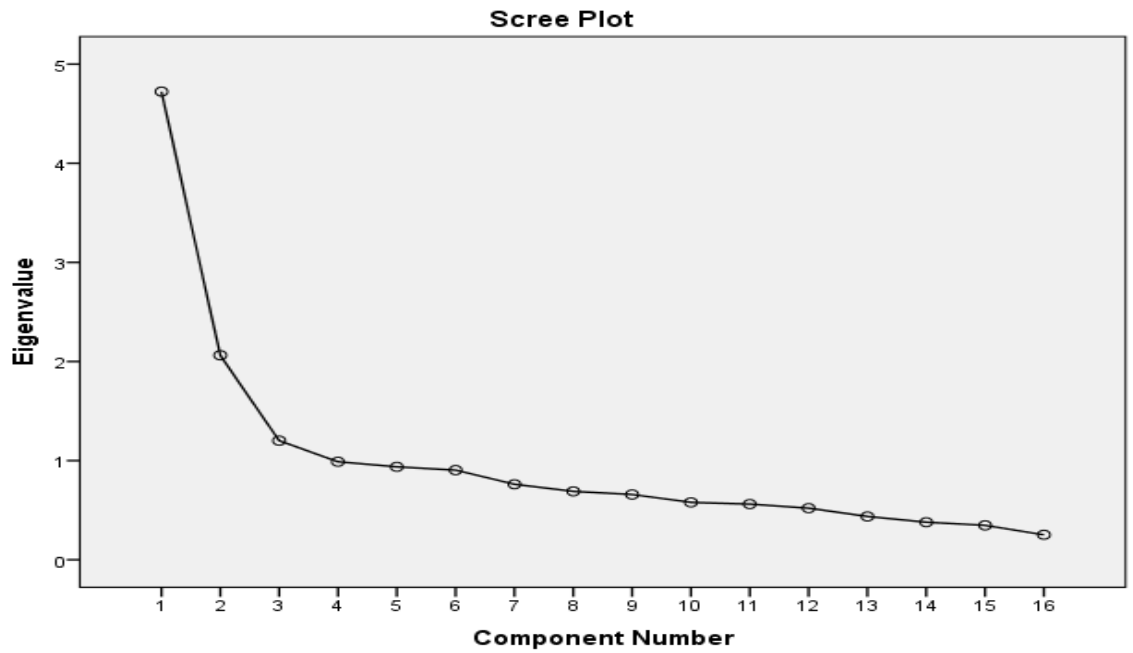

Şekil 1. ÜÇ Faktörlü Yapıya Ait Scree Plot Grafiği

Scree Plot grafiğinde iki nokta arası bir faktörü ifade eder. Bu tabloda eğrinin düzleşerek devam ettiği nokta bulunur ve kaç faktör olduğu sayılır (Büyüköztürk, 2012). Şekil 1 incelendiğinde eğrinin 3. noktadan sonra düzleşerek devam ettiği görülmekte ve yapının 3 faktörlü olduğu ortaya çıkmaktadır.

Ölçeğin ve alt boyutlarının güvenirliğine ilişkin bulgular Tablo 3'te açıklanmıştır.

Tablo 3. Güvenirlik Katsayıları

\begin{tabular}{ccc}
\hline Alt boyut & Cronbach Alfa & Test Tekrar Testi \\
\hline Karşılıklık & .82 & .91 \\
Duygusal Kontrol & .75 & .86
\end{tabular}


Tablo 3'teki veriler incelendiğinde ölçeğin güvenilirlik katsayıları incelenmiştir. Ölçeğin güvenilirlik katsayısı için Cronbach Alfa değerlerine bakılmıştır. Güvenilir bir ölçek için Cronbach Alpha değerinin 0,70'in üzeri olması beklenir (Eymen, 2007). Yukarıdaki tabloda da gösterildiği gibi ölçeğin geneli için Cronbach Alfa değeri .81 olduğu görülmektedir ve ölçüt olarak kabul edilen 0,70 üzerindedir. Ölçeğin "Karşılıklık" ve "Duygusal Kontrol" alt boyutları için Cronbach Alpha değerleri sırasıyla $.81, .75$ ve .61 bulunmuştur. Alt boyutlardan ikisinin Cronbach Alpha değeri ölçüt kabul edilen 0.70 üzerindedir. Sadece "Farklılaşma" alt boyut 0.70 değerinin altında bir değer almıştır. İç tutarlılık katsayısı madde sayısına da bağlı olduğu için madde sayısının az olduğu alt boyutlarda 0,70 yakın değerler de kabul edilebilir (Zekioğlu, Tatar, Bahadır ve Afacan, 2017). Bu veriye dayanarak sadece üç maddeden oluşan ve az sayıdaki maddelerden dolayı birbiriyle daha az örüntü oluşturan "Farklılaşma" alt boyutu için gözlenen .61 Cronbach Alfa değeri de kabul edilebilir seviyededir.

Ölçeğin ölçtüğü nitelik açısından zaman bağlamında kararlılığını istatistiksel olarak test etmek için test-tekrar test yöntemi kullanılmıştır. Ölçeğin test-tekrar test güvenirlik katsayısını belirleyebilmek için ölçek, çalışma grubuna iki hafta ara ile iki kez uygulanmış ve her iki uygulamadan aldıkları puanlar arasındaki kararlılığı test etmek için Pearson momentler çarpım korelasyon katsayısına bakılmıştır. Test tekrar test sonucuna göre ölçeğin birinci ve ikinci uygulaması arasında yüksek düzeyde, pozitif ve anlamlı bir ilişki olduğu görülmüştür ( $r=.90$, p<.05). Ölçeğin alt boyutları arasında da yüksek düzeyde pozitif ve anlamlı bir ilişki olduğu ortaya çıkmıştır $(.92, .86$. ve ,80).

DFA, verinin temelindeki yapıyı değerlendiren açıklayıcı faktör analizinin (AFA) bir uzantısıdır. AFA, bir belirleme işlevini denence kurmaya yönelik bilgi edinilmesini sağlamaya çalışırken DFA, belirlenen bu faktörler arasında yeterli düzeyde ilişkinin olup olmadığını, hangi değişkenlerin hangi faktörlerle ilişkili olduğunu, faktörlerin birbirlerinden bağımsız olup olmadığını, faktörlerin modeli açıklamakta yeterli olup olmadığını sınamak için kullanılır (Özdamar, 2004). DFA'nın çok sayıda varsayımı 
vardır. Bunlardan bazıları hem AFA için hem de DFA için geçerli olan Kaiser-Mayer-Olkin (KMO) değeri, Bartlett Testi ve Korelasyon Matrisidir. Bundan dolayı hem AFA hem de DFA için geçerli olan KaiserMayer-Olkin (KMO) değeri, Bartlett Testi ve Korelasyon Matrisi varsayımları karşılanmış ve aynı veri seti üzerinden DFA yapılmıştır.

DFA'da sınanan modelin uyum yeterliğini belirlemek için pek çok uyum indeksi kullanılmaktadır. Uyum indekslerinden en sık kullanılanları Ki-Kare Uyum Testi (Chi-Square Goodness), İyilik Uyum İndeksi (Goodness of Fit Index, GFI), Düzeltilmiş İyilik Uyum İndeksi (Adjusted Goodness of Fit Index, AGFI), Karşılaştırmalı Uyum İndeksi (Comparative Fit Index, CFI), Normlaştırılmış Uyum İndeksi (Normed Fit Index, NFI), Ortalama Hataların Karekökü (Root Mean Square Residuals, RMR veya RMS) ve Yaklaşık Hataların Ortalama Karekökü'dür (Root Mean Square Error of Approximation, RMSEA).

GFI, CFI, NFI, RFI, IFI ve AGFI indeksleri için kabul edilebilir uyum değeri 0.90 ve mükemmel uyum değeri 0.95 olarak kabul edilmektedir. RMSEA için ise 0.08 kabul edilebilir uyum ve 0.05 mükemmel uyum değeri olarak kabul edilmiştir (Bentler and Bonett, 1980). Ayrıca $\chi 2$ değerinin serbestlik derecesine bölünmesiyle elde edilen değer, 2,00 veya altında ve " $\mathrm{p}$ " değerinin de anlamlı olması için 0.05'in altında olması gerekir (Munro, 2005). Maddelere yüklenen faktör yükleri ise 0 ile 1 arasında değer alır ve kabul edilebilir olması için 0.30 'un üstünde olması gerekir (Harrington, 2009).

Yapılan DFA sonucu elde edilen Ki-kare değeri ve madde faktör yüklerine ilişkin bulgular Şekil 2' de verilmiştir.

Şekil 2'de verilen path diyagramı incelenmiş ve minimum Ki-kare değerinin ( $\chi 2=187.32, \quad \mathrm{~N}=101, \mathrm{p}=0.00)$ anlamlı olduğu görülmüştür (187.32/101=1.85). Maddelere yüklenen faktör yükleri ise, kabul edilebilir ölçüt olan 0,30'un üstünde olduğu ortaya çıkmıştır (en düşük 0,38 ve en yüksek 0,77). Ayrıca RMSEA uyum indeksi değerleri incelendiğinde 0.061 sonucu elde edilmiş ve bu uyum indeksi değerinin kabul edilebilir derecede $(0,05 \leq . \times \leq .0,08)$ olduğu ortaya çıkmıştır (Marsh, Hau, Artelt, Baumert and Peschar, 2006). 


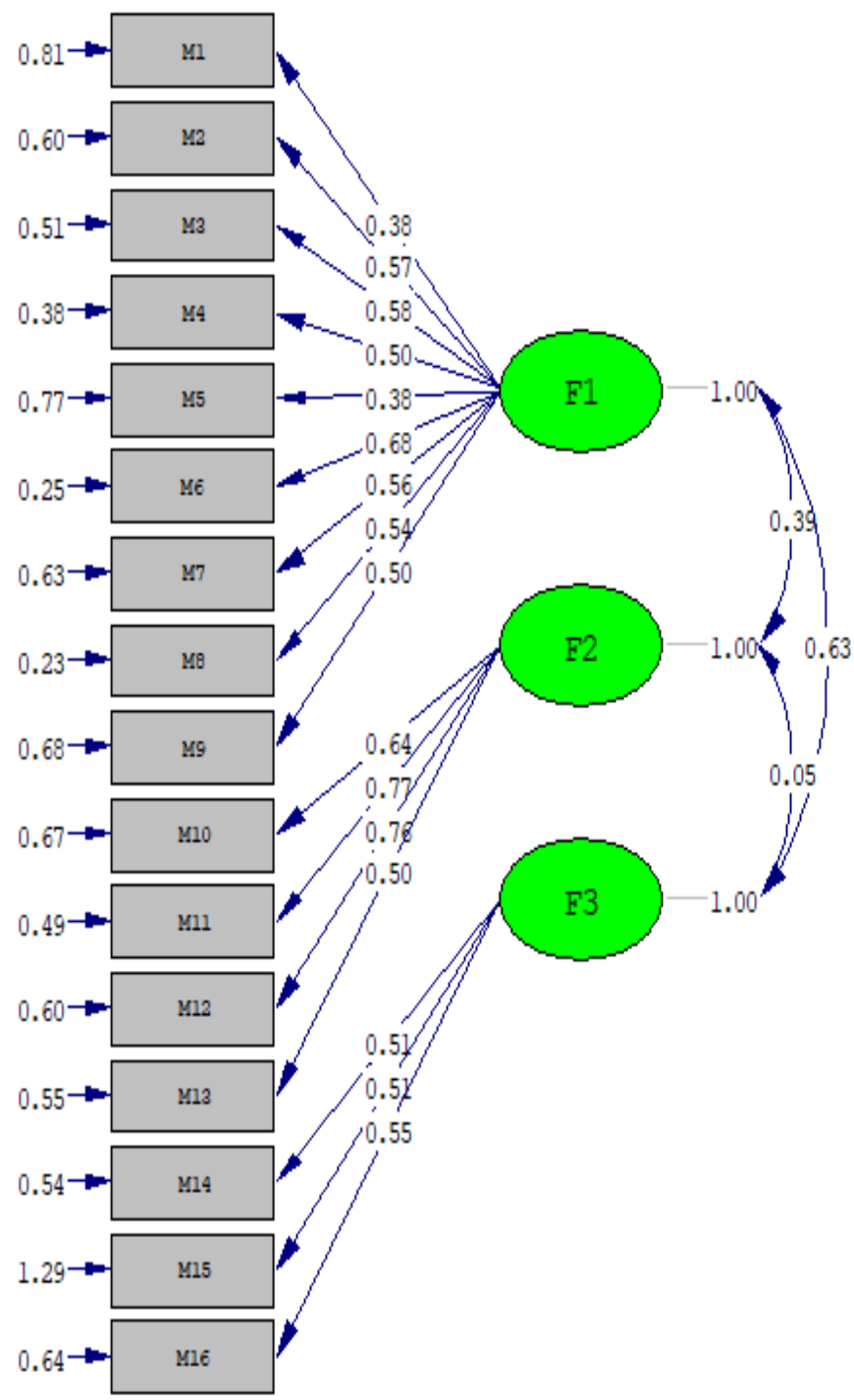

Chi-Square $=187.32, \mathrm{df}=101, \mathrm{P}$-value $=0.00000, \mathrm{RMSEA}=0.061$

Şekil 2. İlişki Özyeterlik Ölçeğine Ait Path Diyagramı

Yapılan DFA sonucu elde edilen uyum indeksi değerleri Tablo 4'te gösterilmiştir. 
Tablo 4. Uyum İndeksi Değerleri

\begin{tabular}{lllll}
\hline İndeksler & $\begin{array}{l}\text { Mükemmel } \\
\text { Uyum Ölçütü }\end{array}$ & $\begin{array}{l}\text { Kabul Edilebi- } \\
\text { lir Uyum Öl- } \\
\text { çütü* }\end{array}$ & Bulgu & Sonuç \\
\hline$\chi 2 /$ sd & $0-2.5$ & $2.5-3$ & 1.854 & Mükemmel \\
RMSEA & $\leq .005$ & $\leq .008$ & 0.061 & Kabul edilebilir \\
RMR & $\leq .005$ & $\leq .008$ & 0.059 & Kabul edilebilir \\
SRMR & $\leq .005$ & $\leq .008$ & 0.063 & Kabul edilebilir \\
NFI & $\geq .95$ & $\geq .90$ & 0.91 & Kabul edilebilir \\
NNFI & $\geq .95$ & $\geq .90$ & 0.95 & Mükemmel \\
CFI & $\geq .95$ & $\geq .90$ & 0.95 & Mükemmel \\
IFI & $\geq .95$ & $\geq .90$ & 0.95 & Mükemmel \\
RFI & $\geq .95$ & $\geq .90$ & 0.90 & Kabul edilebilir \\
GFI & $\geq .90$ & $\geq .85$ & 0.91 & Mükemmel \\
AGFI & $\geq .90$ & $\geq .85$ & 0.89 & Kabul edilebilir \\
\hline
\end{tabular}

(Marsh, Hau, Artelt, Baumert and Peschar, 2006)

Tablo 4'teki uyum indeksi değerleri incelendiğinde RMSEA=0.061, $\mathrm{NFI}=0.91, \mathrm{CFI}=0.95, \mathrm{IFI}=0.95, \mathrm{RFI}=0.90, \mathrm{GFI}=0.91$ ve $\mathrm{AGFI}=0.89$ olarak bulunmuştur. Bu uyum indeksi değerleri modelin kabul edilebilir derecede uyumlu olduğunu ortaya koymuştur. Path diyagramı çizdirildikten sonra ilk iş olarak maddelerin $t$ değerleri kontrol edilir. T değeri 1.96'y1 aşarsa 0.05, 2.56'yı aşarsa 0.001 düzeyinde anlamlıdır. Anlamsız olanların ölçekten çıkarılması gerekir (Şimşek, 2007). T değerlerini gösteren bulgular Şekil 3'te açılanmıştır.

Şekil 3'teki $t$ değerlerini incelendiğinde her bir maddenin $t$ değerinin ölçüt kabul edilen 2,56'ın çok üzerinde kabul edilebilir bir düzeyde olduğu görülmektedir (En düşük= 5.00; en yüksek=14.02). 


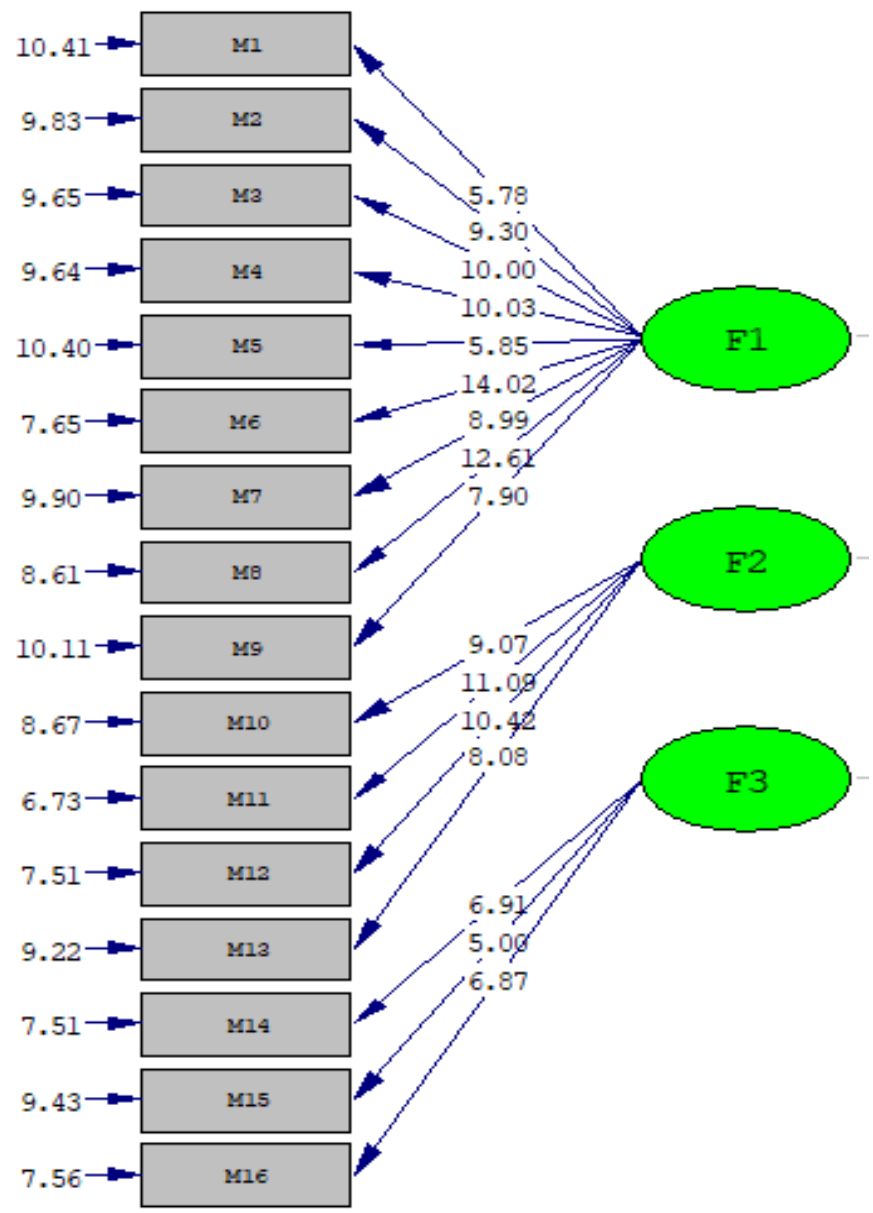

Chi-Square $=187.32, \mathrm{df}=101, \mathrm{P}$-value $=0.00000, \mathrm{RMSEA}=0.061$

Şekil 3. T Değerlerini Gösteren Diyagram

\section{Tartışma ve Sonuç}

Ölçeğin orjinal formunda 'Farklılaşma' alt boyutunda yer alan 2 madde ve 'Karşılıklık' alt boyutunda 7 madde Türkiye kültüründe işlenmemiştir. 'Duygusal Kontrol' alt boyutunda yer alan maddeler ise Türk kültürüyle birebir örtüşmektedir. Türkiye'de eşler duyguları bastıran ataerkil bir kültürde büyüdükleri için duyguları göstermekten ziyade saklamayı tercih etmekte (Kocacık, 2004) ve duygusal ihtiyaçları bir sorun kaynağı 
olarak görmemektedir. Ölçeğin geliştirdiği ülke olan Amerika'da gelişmiş bir kültüre sahip olduğu için duygusal sorunlar yapıcı yollarla çözüme kavuşmakta, ölçeğin uyarlandığı kültür olan Türkiye'de ise duygusal sorunlar ortaya çıkmadığ 1 için çatışmalara sebep olmamakta ve bu nedenle iki kültür "Duygusal Kontrol” konusunda farklı sebeplerle benzer özellik gösterebilmektedir.

"Farklılaşma" alt boyutunda iki madde uyarlandığı kültürde işlenmemiştir. Aslında hem Amerika hem de Türkiye farklı kültürel özellklere sahip insanların bir arada yaşadığı ülkeler olarak benzerlik göstermektedir. Fakat evrensel değerlerin Amerikada daha fazla özümsenmesi ve Türkiye'de farklılıklara hoşgörünün yeterince işselleştirilememesinden dolayı iki kültür arasında az da olsa farklılık gösterebilmektedir. Türkiye' de farklı özelliklere sahip bireyler Amerika'daki bireylere göre kolayca evlenememektedir, evlenseler bile daha sonra hem eşlerin hem de eşlerin ailelerinin anlaşmazlıklarından kaynaklı sorunlar ortaya çıkabilmektedir. Bunlardan dolayı "Eşimle aramdaki olası dini ve ahlaki değer farklılıklarıyla baş ederim" gibi maddelerin Türkiye'de işlenmemesi olası görülmektedir.

Karşılıklık alt boyutunda 7 madde uyarlandığ 1 kültürde işlenmemiştir. Bunun temel sebebi Türkiye'nin ölçeğin geliştirdiği kültür olan Amerika'ya göre ataerkil yapının daha güçlü olması ve ataerkil yapıda güç üzerine kurulu tek taraflı ilişkilerin yaygın olmasıdır. Tek taraflı ilişkilere zemin hazırlayan temel faktör, toplumsal cinsiyet roller üzerine ilişkilerin kurulmasıdır. Toplumsal cinsiyet, kadınların ve erkeklerin davranışlarını nasıl olması gerektiğini tanımlayan toplumun belirlediği birtakım rolleri içeren kurallardır (Çıtak, 2008). Ataerkil düzende toplumsal cinsiyet rolleri daha fazla benimsenmektedir. Ataerkil yapıda toplumsal cinsiyet rolleri gereği, kadının erkeğe ait olduğu anlayışı erkeğe güç vermektedir ve erkeklerin ilişkide istek ve ihtiyaçları daha çok ön plana çıkmaktadır (Mutluer, 2011; Kahraman, Ozansoy, Akıllı, Kekillioğlu ve Özcan, 2014). İlişkide erkeklerin isteklerin yerine getirilmemesi veya uygun görmediği bir şeylerin yapılması büyük sorun sebebi olarak görülmektedir. Akçelik (2016) tarafından toplumsal cinsiyet ile ilgili yapılan bir araştırmada eşine şiddet uygulayan erkeklerin geleneksel cinsiyet rollerine sıkı bağlı olduğu, kendini aile reisi olarak gördüğü ve şiddeti doğal karşıladığı, kocaya itaat etmemeyi ve saygısızlığı şiddetin 
sebebi olarak gördüğü ortaya çıkmıştır. Eş şiddeti ile ilgili yapılan bir araştırmada ise saldırgan erkeğin uyguladığı şiddetin sebebini genellikle şiddet mağduru eşinde gördüğü ve onu suçladığı ortaya çıkmıştır (Birkley ve Eckhardt, 2015). Bunlardan dolayı Ataerkil yapıda erkek endeksli ilişkilerin yaşandığı Türkiye'de "Karşılıklık" alt boyutunda yer alan "İlişkide benden kaynaklanan hataları kabullenirim", "Eşimin kendisiyle ilgili isteklerini kendi yöntemleriyle yapmasını kabul ederim" ve "Eşimin diğer insanlarla vakit geçirme isteğini kabul ederim" gibi maddelerin işlenememesi olası görülmektedir.

Sonuç olarak 'İlişki Özyeterlik Ölçeği'nin geliştirildiği kültürdeki orijinal formu, 25 maddeden ve 3 alt boyuttan oluşmaktadır. Yapılan açımlayıcı ve doğrulayıcı faktör analizi sonuçları, ölçeğin orijinal formunda olduğu gibi 3 alt boyutlu bir yapıda olduğunu ortaya koymuştur. Alt faktörlere yüklenen maddeler, ölçeğin geliştirdiği kültürdeki orijinal formunda alt boyutlara yüklenen maddelerle birebir paralellik göstermektedir. Sadece ölçeğin özgün formunda yer alan 9 madde uyarlanan kültürde işlemediği ortaya çımış ve ölçek 16 maddelik 3 alt boyutlu formuyla Türkiye'deki 18 yaş üstü bireylere uygulanabilir geçerli ve güvenilir bir ölçek olduğu sonucuna varılmıştır. Ölçeğin tüm maddeleri olumludur ve ölçekte olumsuz puanlanan madde yoktur. Puanlama, 16 ile 80 puan aralığında değişmektedir. Ölçek, 5'li likert tipi ölçeğe göre düzenlenmiştir. Ölçekten alınan yüksek puanlar, ilişki özyeterli seviyesinin yüksek olduğunu göstermektedir.

Eşler arasında ilişki özyeterlik düzeyini ölçmeye yönelik geliştirilmiş olan bu ölçek, yurtdışında pek çok çalışmada kullanılmıştır. Geçerliği ve güvenirliği yüksek olan bu ölçeği Türk kültürüne kazandırmak, ilgili alanyazında yapılacak diğer ilişki çalışmalarına 1şık tutacaktır. İlişki özyeterliğin eşler arasında yaşanan romantik kıskançlık, şiddet ve bağlanma stilleri gibi kavramlarla arasındaki ilişkiyi ortaya çıkaracak yeni çalışmaların yapılması evlilik ve aile psikolojik danışmanlığı alanına katkı sağlayacağı düşünülmektedir. 
EXTENDED ABSTRACT

\title{
Adaptation of Relationship Self-Efficacy Scale to Turkish: Validity And Reliability Study
}

\author{
Yunus Akan
}

Muş Alparslan University

One of the most important developmental tasks of an adultis to establish and maintain a satisfying, genuine and close relationship. In order to do this, relationship self-efficacy, which expresses an individuals' belief in theircapacity to establish and maintain satisfactory relationships should be developed. In particular, self-efficacy can help the relationship between partners; rather than fleeing fromrelationships, an individual may be more willing to be intimate, solve problems during disputes, provide support to theirpartner, respect differences, develop common understandings, practice open communication and continue in the relationship. All of these factors affect the quality of the relationship between spouses and the satisfaction they obtain from a relationship. The aim of this study was to adapt the Relationship Self-Efficacy Scale developed by Lopez et al.

In the proess of adapting the scale, the 35 items in the original English version ofthe scale were translated into Turkish by the researcher and then by four experts in the field. Then these translations were compared, shared expressions were noted and thedifferences were assimilated within a new statement. The Turkish form, based on expert opinion, was then translated back into English. The original Turkish version of the scale and the translation of this back into English were examined by four experts and it was concluded that there was no difference between the two. The opinions of Turkish experts about the original form was sought and their recommendations were taken into account. This first version of the form was tested in terms of its application and suitability to Turkish individuals over the age of 18 . The form was then tested on ten Turkish adults. As a result of the feedback, the scale was finalized and made ready to be implemented. 230 adults who lived in Mersin and had a partner (a spouse, a fiancé/fiancée, or long-term partner) filled in the scale twice over a 
period of two weeks. $56.5 \%$ of the participants were male and $43.5 \%$ were female, and their ages ranged from 18 to 50 years old. The scale has 25 items and three factors in its original form. There are no negative points in the scale. High scores from the scale indicate that the level of relationship self-efficacy is high. For the validity of the scale, confirmatory factor analysis was performed using explanatory factor analysis and the Lisrel 9.2 program in the SPSS 21 on the35-item form. Since there is a multifactorial structure, there is a high level of correlation between all factors, and varimax is rotated by the vertical rotation technique to ensure that the factor variance is maximized for better interpretation. In order to test the reliability of the scale, the Cronbach's alpha value and test-retest correlation coefficient were calculated.

The KMO value was found to be .85 , and this was found to be excellent and sufficient. As a result of Bartlett'ssphericity test, the chi-square value was found to be statistically significant $[X 2=2967.509 ; p=0.00)$. In the exploratory factor analysis, a 3-factor structure with an eigen value above 1 , having at least three substances, having a variance of more than $5 \%$ and explaining $49.91 \%$ of the total variance was obtained. As a result of the confirmatory factor analysis, the fit index values were found to be significant: $\mathrm{RMSEA}=0.061, \mathrm{NFI}=0.91, \mathrm{CFI}=0.95, \mathrm{IFI}=0.95, \mathrm{RFI}=0.90, \mathrm{GFI}=$ 0.91 and AGFI $=0.89$. In addition, in the confirmatory factor analysis, the $t$ value of each item was found to be acceptable ( $t>2.56)$. In the reliability study, the Cronbach'salpha value for the whole scale was .81. For the subdimensions of Mutuality, Emotional Control and Differentiation, the results were $.81, .75$ and .61 , respectively. The test-retest correlation coefficient was .90 for the whole scale, and $.92, .86$, and .80 for the sub-dimensions, respectively.

The results of the exploratory and confirmatory factor analysis revealed that the scale had a 3-dimensional structure, as in the original version. The items loaded on the sub-factors were in parallel with the items loaded on the sub-dimensions in the original form in the culture developed by the scale. Only the scale of the 9 substances adapted the original form of culture that emerged in the processing and scale applicable to individuals over the age of 18 in Turkey with its 16 sub-article 3-dimensional form. It was concluded that the scale wasvalid and reliable. This scale, which was developed to measure the level of self-efficacy in the 
relationship between spouses, has been used in many studies worldwide.Using this scale, which has a high validity and reliability, within a Turkish context will shed light on other relationship studies conducted in Turkey and around the world.

\section{Kaynakça / References}

Akan, Y. ve Kıran, B. (2017). Erkeklerin şiddete maruz kalma ve şiddet uygulama yaşantıları arasındaki ilişkinin incelenmesi. International Journal of Education Technology and Scientific Researches, 2 (2), 47-71.

Akçelik, B.C. (2016). Cinsiyetçi Ve Saldırgan Tutumlar İle Kadına Yönelik Aile İçi Şiddeti Doğal Görme Arasındaki İlişkinin İncelenmesi, (Yayınlanmamış Yüksek Lisans Tezi). Beykent Üniversitesi, Sosyal Bilimler Enstitüsü, İstanbul.

Ayan, S. (2013). Kasten adam öldürme suçu işlemiş hükümlü erkeklerin bağlanma stillerinin, çocukluk çağı travmalarının ve öfke ifade biçimlerinin incelenmesi, (Yayınlanmamış Yüksek Lisans Tezi). Maltepe Üniversitesi, Sosyal Bilimler Enstitüsü, İstanbul.

Bandura, A. (1997). Self-efficacy: the exercise of control. New York: W.H. Freedmanand Company.

Bentler, P. M., ve Bonett, D. G. (1980). Significance tests and goodness of fit in the analysis of covariance structures. Psychological Bulletin, 88(3), 588-606.

Birkley E., Eckhardt, C. (2015). Anger, hostility, internalizing negative emotions, and intimate partner violence perpetration: A meta-analytic review. Clinical Psychology Review 37(4), 40-56.

Büyüköztürk, Ş. (2012). Sosyal bilimler için veri analizi el kitabı (17. Baskı). Ankara: Pegem A Yayıncilık.

Canary, D. J., ve Stafford, L. (1992). Relational maintenance strategies and equity in marriage. Communication Monographs, 59, 243-267.

Cassidy, J. (2001). Truth, lies, and intimacy: an attachment perspective. Attachment and Human Development, 3, 121-155. 
Collins, N. L., Cooper, M. L., Albino, A., ve Allard, L. (2002). Psychosocial vulnerability from adolescence to adulthood: a prospective study of attachment style differences in relationship functioning and partner choice. Journal of Personality, 70, 965-1008.

Craparo, G., Gori, A., Petruccelli, I., Cannella, V., ve Simonelli, C. (2014). Intimate partner violence: relationships between alexithymia, depression, attachment styles and coping strategies of battered women. The Journal of Sexual Medicine, 11(6),1484- 1494.

Çıtak, A. (2008). Kadınlarm çalışmasına yönelik tutum: Cinsiyet, cinsiyet rolü ve sosyoekonomik düzeye göre bir karşılaştırma. (Yayınlanmamış Yüksek Lisans Tezi). Ankara Üniversitesi, Sosyal Bilimler Enstitüsü, Ankara.

Çimen, S. (2007). Illköğretim öğretmenlerinin tükenmişlik yaşantıları ve yeterlik algıları. (Yayınlanmamış Yüksek Lisans Tezi). Kocaeli Üniversitesi Sosyal Bilimler Enstitüsü, Kocaeli.

Doğan, S. (2013). Sinıf öğretmenlerinin özyeterlik algısı ve öğretmenlik mesleğine yönelik tutumlarmm incelenmesi (Ă̆gr İli Örneği). (Yayımlanmamış Yüksek Lisans Tezi). Erzincan Üniversitesi, Sosyal Bilimler Enstitüsü, Erzincan.

Dutton, D.G. (2010). The abusive personality, 2nd Ed. New York: Guilford Press, S. 178-190.

Eymen, U. E. (2007). SPSS 15.0 Veri analiz yöntemleri. İstatistik Merkezi Yayin, (1), 167.

Gençtürk, A. (2008). İlköğretim okulu öğretmenlerinin özyeterlik algıları ve iş doyumlarının çeşitli değişkenler açısından incelenmesi. Yüksek Lisans Tezi, Zonguldak Karaelmas Üniversitesi, Sosyal Bilimler Enstitüsü, Zonguldak.

Harvey, J. H., ve Omarzu, J. (1997). Minding the close relationship. Personality and Social Psychology Review, 1, 224-240.

Harrington, D. (2009). Confirmatory factor analysis. Oxford University: Press.

Jacobson, N., ve Gottman. F. (1998). When men batter women: new insights into ending abusive relationships. New York: Simon And Schuster.

Kalaycı, Ş. (2014). SPSS uygulamal çok değiş̧kenli istatistik (6. Basım). Ankara: Asil Yayın Dağıtım. 
Karahan, S. ve Balat, G. U. (2011). Özel eğitim okullarında çalışan eğitimcilerin özyeterlik algılarının ve tükenmişlik düzeylerinin incelenmesi. Pamukkale Üniversitesi Eğitim Fakültesi Dergisi, 29, 114.

Kahraman, L., Kahraman, A. B., Ozansoy, N., Akılll, H., Kekillioğlu, A. ve Özcan, A. (2014) Nevşehir Hacı Bektaş Veli Üniversitesi toplumsal cinsiyet alg1sı araştırması. Turkish Studies, 9(2), 811-831.

Kline, P. (1994). An easy guide to factor analysis. New York: Routledge.

Kocacık, F. (2004). Aile içi ilişkilerde kadına yönelik şiddet: Türkiye'den örnekler. Sivas: Cumhuriyet Üniversitesi Yayınları.

Lopez, F. G., ve Lent, R. W. (1991). Efficacy-based predictors of relationship adjustment and persistence among college students. Journal of College Student Development, 32, 223-230.

Lopez, F. G., Morúa, W., ve Rice, K. G. (2007). Factor structure, stability, and predictive validity of college student's relationship self-efficacy beliefs. Measurement and Evaluation in Counseling and Development, 40, 80-96.

Marsh, H. W., Hau, K.T., Artelt, C., Baumert, J., ve Peschar, J. L. (2006). OECD's Brief Self-Report Measure of Educational Psychology's Most Useful Affective Constructs: Cross-Cultural, Psychometric Comparisons Across 25 Countries. International Journal of Testing, 6(4), 311-360

Mccrudden, M. T., Perkins, P. G., ve Putney, L. G. (2005). Self-Efficacy and interest in the use of reading strategies. Journal of Research In Childhood Education, 20(2), 119-131.

Munro, B. H. (2005). Statistical methods for health care research (Vol. 1). Lippincott Williams \& Wilkins.

Mutluer, N. (2011). Actics in between: Gendered citizenship and every day life of internally displaced man in Tarlabasi, İstanbul. Doktora Tezi, Central European University, Yurtdışı Enstittüsü, Budapeşte.

Özdamar, K. (2004). Güvenirlik ve soru analizi. Paket programlarla istatistiksel veri analizi-1. 5th ed. Eskişehir: Kaan Kitabevi.

Peralta, R. L., Tuttle, L. A. ve Steele, J. L. (2010). At the intersection of interpersonal violence, masculinity, and alcohol use: the experiences of heterosexual male perpetrators of intimate partner violence. $\mathrm{Vi}$ olence Against Women, 16, 387-409. 
Riggs, D. S., Caulfield, M. B., ve Street, A. E. (2000). Risk for domestic violence: factors associated with perpetration and victimization. Journal of Clinical Psychology, 56(10), 1289-1316.7.

Sahranç, Ü. (2007). Stres kontrolü, genel özyeterlik, durumluk kaygı ve yaşam doyumuyla ilişkili bir akış modeli. Doktora Tezi, Gazi Üniversitesi, Eğitim Bilimleri Enstitüsü, Ankara.

Seçer, İ. (2015). SPSS ve lisrel ile pratik veri analizi. Ankara: Anı Yayıncıllk

Şimşek, Ö. F. (2007). Yapısal eşitlik modellemesine giriş: temel ilkeler ve lisrel uygulamaları. Ankara: Ekinoks, 315-337.

Tabachnick, B.G. ve Fidell, L.S. (2001). Using multivariate statistics. Needham Heights: Allyn ve Bacon.

Tabachnick, B. G., ve Fidell, L. S. (2007). Using multivariate statistics (5. Bask1). Boston: Allyn and Bacon.

Zekioğlu, A., Tatar, A., Bahadır, E. ve Afacan, E. (2017) Zihinsel hazır oluşun ölçülmesi: ölçek geliştirme çalışması. Spormetre Dergisi, 2017, 15 (2), 57-64.

Zengin, U. (2003). İlköğretim öğretmenlerinin özyeterlik algıları ve sımı içi iletişim örüntüleri (Yayımlanmamış Yüksek Lisans Tezi). Dokuz Eylül Üniversitesi, Eğitim Bilimleri Enstitüsü, İzmir.

\section{Kaynakça Bilgisi / Citation Information}

Akan, Y. (2019). İlişki özyeterlik ölçeğinin Türkçeye uyarlanması: Geçerlik ve güvenirlik çalışması. OPUS-Uluslararası Toplum Araştırmalarn Dergisi, 10(17), 1601-1624. DOI: 10.26466/opus.510391 